\title{
The role of selected adipokines and ghrelin in the prognosis after myocardial infarction in a 12-month follow-up in the presence of metabolic syndrome
}

Błażej Michalski ${ }^{1}$, Ewa Szymczyk ${ }^{1}$, Lukasz Peczek², Barbara Nawrot ${ }^{2}$, Karolina Kupczynska ${ }^{1}$,

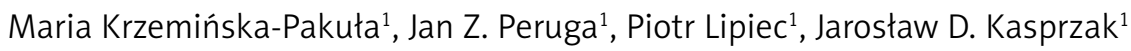

${ }^{1}$ Department of Cardiology, Medical University of Lodz, Lodz, Poland

${ }^{2}$ Department of Bioorganic Chemistry, Centre of Molecular and Macromolecular Studies of the Polish Academy of Sciences, Lodz, Poland

Submitted: 14 June 2016

Accepted: 26 September 2016

Arch Med Sci 2017; 13, 4: 785-794

DOI: https://doi.org/10.5114/aoms.2017.65659

Copyright (c) 2017 Termedia \& Banach

\section{Abstract}

Introduction: The aim of this study was to evaluate the predictive value of selected adipokines in the improvement in the ejection fraction and in the development of adverse cardiac remodeling during 12 months of follow-up among patients with an ST-segment elevation acute myocardial infarction (STEMI) in the presence of metabolic syndrome (MeS).

Material and methods: The study population consisted of 69 patients (49 male; mean age: $59 \pm 10$ years) with a first STEMI that was treated with a primary percutaneous coronary intervention ( $\mathrm{pPCl}$ ). In this group, 36 patients (18 male; mean age: $60 \pm 15$ years) had MeS according to the definition of the International Diabetes Federation. The baseline clinical evaluation included a clinical examination and evaluation of the blood levels of C-reactive protein, ghrelin, resistin, and fasting glucose. Within $72 \mathrm{~h}$ after the STEMI, an echocardiographic examination was performed. A complete clinical evaluation was repeated after 12 months. Adverse cardiac remodeling was defined as an increase in the left ventricular end-diastolic volume of $\geq 8 \%$. An improvement of the ejection fraction (EF) was defined as an increase of more than $5 \%$ in the EF.

Results: A concentration of ghrelin $\leq 160.46 \mathrm{pg} / \mathrm{ml}(\mathrm{AUC}=0.71, p=0.032)$ had a good predictive value for the occurrence of adverse left ventricular remodeling but only in the patients without MeS. Among the patients with MeS, a concentration of resistin $\leq 5196 \mathrm{pg} / \mathrm{ml}(\mathrm{AUC}=0.073, p=0.024)$ had a good predictive value for the occurrence of left ventricular remodeling. A concentration of leptin $>52.18 \mathrm{pg} / \mathrm{ml}(\mathrm{AUC}=0.81, p<0.0001)$ and resistin $>4419.27 \mathrm{ng} / \mathrm{ml}$ ( $A \cup C=0.67, p=0.049$ ) had a good predictive value for improvement of the LVEF in the patients without MeS.

Conclusions: The selected adipokines had a good predictive value for the development of adverse cardiac remodeling and for improvement of the ejection fraction among patients after a STEMI in the presence of metabolic syndrome.

Key words: myocardial infarction, adipokines, ghrelin, metabolic syndrome, echocardiography.

\section{Introduction}

Metabolic syndrome (MeS) is one of the most important medical challenges of the twenty-first century. The syndrome involves a constellation of

\author{
Corresponding author: \\ Błażej Michalski \\ Department of Cardiology \\ Medical University of Lodz \\ $1 / 5$ Kniaziewicza St \\ 91-347 Lodz, Poland \\ Phone: +48 4221363 12, \\ +48501681795 \\ E-mail: bwmichalski@op.pl
}


abnormalities that increase the risk of developing type 2 diabetes and cardiovascular diseases. Metabolic syndrome is characterized by obesity, hypertension, dyslipidemia, insulin resistance, diabetes mellitus, an abnormal concentration of cytokines and the presence of inflammatory markers. Expert consultants with the WHO have concluded that further research on metabolic syndrome should focus on the evaluation of metabolic pathways leading to the increased risk of developing diabetes mellitus and cardiovascular disease (CVD) [1]. Between 1999 and 2002, 44\% of overweight or obese adolescents suffered from metabolic syndrome [2]. In the U.S., approximately 1 in 4 adults older than age 20 is diagnosed with metabolic syndrome [3]. A meta-analysis of prospective studies by Gami et al. concluded that MeS increases the risk of developing CVD (summary RR $=1.78$; 95\% Cl: $1.58-2.00$ ) [4]. The combination of abdominal obesity, elevated blood pressure and hyperglycemia constituted the greatest risk for developing CVD (hazard ratio $(\mathrm{HR})=2.36 ; 95 \% \mathrm{Cl}: 1.5-3.61)$ and for mortality $(\mathrm{HR}=3.09 ; 95 \% \mathrm{Cl}: 1.93-4.94)$ in the Framingham Offspring Study [5]. Previous studies have focused on the role of specific biomarkers in the development of diabetes mellitus (DM) or CVD. We have evaluated the influence of specific adipokines on the prognosis after an acute myocardial infarction (MI) and on improvements in the cardiac function and cardiac remodeling using modern echocardiographic techniques. Despite the development of new strategies for the treatment of acute coronary syndromes (ACSs), their prevalence is still increasing and is currently at $3.1 \%$ in the U.S. population. The average age of the first incident for men is 64.5 years and 70.3 years for women [6]. Although their incidence in the U.S. has decreased from $47.0 \%$ in 1999 to $22.9 \%$, ST-segment elevation acute myocardial infarction (STEMI) infarctions still remain a considerable problem [7].

\section{Adipokines}

Adipose tissue is an active endocrine organ that secretes essential hormones, cytokines, vasoactive substances and peptides. In addition to regulating the fat mass and nutrient status, adipose tissue releases several hormones, including leptin, resistin and ghrelin. Leptin and ghrelin, along with other hormones, are responsible for the appetite and balancing food intake. Discovered in 2001 by three independent groups, resistin is primarily expressed in monocytes and macrophages, showing elevated levels in diet-induced obesity $[8,9]$. An animal model has shown that resistin strongly affects cholesterol metabolism, elevating the total cholesterol and triglyceride concentrations as well as decreasing the level of high-density cholesterol [10]. In recent publications, resistin was used as an independent predictor of major cardiovascular events, including cardiovascular death, $\mathrm{MI}$ and restenosis in patients undergoing percutaneous coronary interventions (PCI) [11]. Ghrelin, a growth hormone-releasing peptide, is the endogenous ligand for the growth hormone secretagogue receptor and has a significant influence on the cardiovascular system. Studies in an animal model by $\mathrm{Li}$ et al. showed that ghrelin inhibited the ventricular remodeling induced by hypertension, and the preventive effect may be mediated by the anti-inflammatory actions of the peroxisome proliferator-activated receptor (PPAR)- $\gamma$-dependent pathway [12].

\section{Material and methods}

Sixty-nine consecutive patients who were admitted to the Cardiology Department of the Medical University of Lodz with ACS with an ST elevation that was confirmed by the coronary angiography occlusion of only one coronary artery were enrolled in our study without regard to their ages (20 females, 49 males). The STEMI diagnosis criteria were as follows: symptoms of ischemia, ST-segment elevation on an ECG and significant troponin elevation, with at least one measurement exceeding the $99^{\text {th }}$ percentile of the reference range. Within $10 \mathrm{~h}$ of the onset of symptoms, all of the patients were successfully treated with a $\mathrm{PCl}$ of one of the coronary arteries. The MeS was defined as having at least 3 of the following 5 conditions set forth by the recent National Cholesterol Education Program (NCEP) Adult Panel III (ATP-III) IDF (International Diabetes Federation) report with modifications: dysglycemia, hypertension, hypertriglyceridemia, a decreased level of high-density lipoprotein (HDL) cholesterol, and obesity $[13,14]$. Dysglycemia was defined as a fasting glucose level > $110 \mathrm{mg} / \mathrm{dl}$; the dysglycemia definition also included the current use of insulin or oral hypoglycemic drugs. Hypertension was defined as a systolic blood pressure $>140 \mathrm{~mm} \mathrm{Hg}$ and/or a diastolic blood pressure $>85 \mathrm{~mm} \mathrm{Hg}$ and the current use of antihypertensive drugs. Hypertriglyceridemia was defined as a serum triglyceride level > $150 \mathrm{mg} / \mathrm{dl}$. Low HDL cholesterol was defined as a serum level $<40 \mathrm{mg} / \mathrm{dl}$ in men and $<50 \mathrm{mg} / \mathrm{dl}$ in women. Abdominal obesity was defined as waist circumference (WC) $>102 \mathrm{~cm}$ for males and $>88 \mathrm{~cm}$ for females. All of the patients were treated with $\mathrm{PCl}$ with stent implantation. The study was approved by the local ethics committee, and written informed consent was obtained from the participants. Patients with a subacute myocardial infarction, myocardial infarction without ST elevation or multi-vessel disease at admittance were not included in the study. To circumvent other potential influences on the plasma levels of adipokines and inflammatory markers, patients 
with any of the following were excluded from the study: infectious diseases, liver insufficiency, hepatitis, a malignancy, autoimmune diseases or a previous myocardial infarction. The weight, height, and waist and hip circumferences were measured using standard methods, and the body mass index (BMI) $\left(\mathrm{kg} / \mathrm{m}^{2}\right)$ and waist-to-hip ratio (WHR) were calculated. There were more women and diabetic patients, and the BMI and WHR were higher among patients with MeS (Table I).

Clopidogrel (a 600-mg loading dose in the emergency room before the cardiac catheterization and then $75 \mathrm{mg} /$ daily for maintenance) and aspirin (a 300-mg loading dose and then $75 \mathrm{mg}$ / daily for maintenance) were administered to the patients undergoing primary stenting. Pharmacological treatment was in accordance with the current guidelines for the management of STEMI. Inclusion in the study had no impact on the further in-hospital and long-term pharmacological management.

\section{Echocardiographic study}

A transthoracic echocardiogram (TTE) was performed in all of the patients to obtain the standard parasternal and apical views using the VIVID 7 and 9 Dimension ultrasound system (GE Healthcare, USA) to evaluate the heart chamber's dimensions, valve function, ejection fraction and diastol- ic function (E/A). The left ventricular (LV) volumes and ejection fraction were calculated using the modified biplane Simpson method. For speckle tracking, according to the technical requirements, a high temporal resolution of the recorded cineloop two-dimensional images (in grayscale) was set to achieve at least 60 frames per second (FPS) or more. The remaining parameters were set automatically using the pre-specified settings of the ultrasound system. The STE analysis included the manual contouring of the LV endocardium and the approval of the proper level of the imaging quality of the analyzed area, including the possible corrections, and the manual performance of further analysis. The left ventricular strain was evaluated off-line using a dedicated workstation with conventional STE software enabling speckle tracking (EchoPac version 6.1.0, GE Healthcare). For this analysis, three separate LV apical views were obtained: four-, two- and three- chamber. Left ventricular remodeling after $\mathrm{MI}$ was defined as a $\geq 8 \%$ increase in the LV end-diastolic volume (LVEDV) [15]. An improvement in the left ventricular ejection fraction was defined as an increase in the LV ejection fraction (LVEF) of > 5\% (Table II).

\section{Laboratory tests}

Blood for the hospital laboratory tests was collected immediately after admission. A sepa-

Table I. Baseline characteristics of study groups

\begin{tabular}{|c|c|c|c|}
\hline Parameter & $\begin{array}{c}\text { Group I } \\
\text { Patients without metabolic } \\
\text { syndrome ( } 33 \text { patients) }\end{array}$ & $\begin{array}{c}\text { Group II } \\
\text { Patients with metabolic syndrome } \\
\text { ( } 36 \text { patients) }\end{array}$ & $P$-value \\
\hline Age [years] & $57 \pm 8$ & $60 \pm 12$ & 0.14 \\
\hline Women $(n)$ & 5 & 15 & \\
\hline Body mass [kg] & $77 \pm 11$ & $91 \pm 13$ & $<0.0001$ \\
\hline $\mathrm{BMI}\left[\mathrm{kg} / \mathrm{m}^{2}\right]$ & $26 \pm 2$ & $33 \pm 4$ & $<0.0001$ \\
\hline WHR & $0.80 \pm 0.1$ & $1.21 \pm 0.1$ & $<0.0001$ \\
\hline Hypertension ( $n$ ) & 35 & 32 & 0.95 \\
\hline Smoking $(n)$ & 15 & 6 & 0.038 \\
\hline Diabetes $(n)$ & 3 & 21 & $<0.0001$ \\
\hline Cholesterol [mg/dl] & $203 \pm 38$ & $204 \pm 34.5$ & 0.93 \\
\hline Triglycerides [mg/dl] & $125 \pm 57$ & $172 \pm 152$ & 0.21 \\
\hline $\mathrm{HDL}[\mathrm{mg} / \mathrm{dl}]$ & $51 \pm 13$ & $44 \pm 11$ & 0.017 \\
\hline LDL [mg/dl] & $127 \pm 31$ & $129 \pm 30$ & 0.86 \\
\hline $\mathrm{HbA}_{1 \mathrm{c}}(\%)$ & $5.7 \pm 0.6$ & $6.6 \pm 0.6$ & $<0.001$ \\
\hline CK MB (mass) [ug/l] & $144 \pm 148$ & $121 \pm 120$ & 0.51 \\
\hline Troponin I [ $\mu \mathrm{g} / \mathrm{l}]$ & $4.2 \pm 3.6$ & $4.4 \pm 4.9$ & 0.9 \\
\hline
\end{tabular}

$B M I$ - body mass index, WHR - waist-to-hip ratio, $H D L$ - high-density lipoprotein, $L D L$ - low-density lipoprotein, $H b A_{1 c}-g l y c a t e d ~$ hemoglobin, CK-MB - creatine kinase-myocardial band, $n$-number of patients. 
Table II. Baseline echocardiographic characteristics

\begin{tabular}{|lccc|}
\hline Variable & $\begin{array}{c}\text { Group I } \\
\text { Patients without MeS } \\
\text { (mean } \pm \text { SD) } \\
\text { (33 patients) }\end{array}$ & $\begin{array}{c}\text { Group II } \\
\text { Patients with MeS } \\
\text { (mean } \pm \text { SD) } \\
\text { (36 patients) }\end{array}$ & $P$-value \\
\hline Left ventricular end-diastolic diameter [mm] & $47 \pm 6$ & $47 \pm 4$ & 0.82 \\
\hline Left ventricular end-systolic diameter [mm] & $33 \pm 5$ & $33 \pm 4$ & 0.94 \\
\hline Left atrial diameter [mm] & $40 \pm 4$ & $41 \pm 4$ & 0.21 \\
\hline Right ventricular diameter [mm] & $26 \pm 3$ & $26 \pm 3$ & 0.63 \\
\hline Left ventricular end-systolic volume [ml] & $68 \pm 16$ & $68 \pm 12$ & 0.83 \\
\hline Left ventricular end-diastolic volume [ml] & $127 \pm 19$ & $128 \pm 22$ & 0.81 \\
\hline EF (\%) (Simpson method) & $43 \pm 8$ & $44 \pm 8$ & 0.15 \\
\hline 2-dimensional strain & $14.1 \pm 8$ & $13.2 \pm 7$ & 0.57 \\
\hline EF- ejection fraction. & & &
\end{tabular}

rate sample for specified biomarkers was collected the day after admission and at 12 months of follow-up. The blood samples for the biomarker testing were collected at 7:00 a.m. after at least $14 \mathrm{~h}$ of fasting. The citrated plasma and serum with the addition of the protease inhibitor AEBSF was stored at $-70^{\circ} \mathrm{C}$ until assaying. The serum concentrations of creatinine, glucose, creatine kinase isoenzyme MB (CK-MB) activity, sodium, potassium, and lipids as well as the serum troponin I levels were measured in the hospital laboratory using standard laboratory methods. Ghrelin was measured by an enzyme-linked immunosorbent assay (ELISA - Millipore Corporation, Billerica, $M A)$, whereas adiponectin, C-reactive protein (CRP), leptin, resistin, myeloperoxidase, interleukin 6, and monocyte chemoattractant protein-1 (MCP-1) were measured using flow cytometry (FACS - Bender MedSystem Flow Cytomix) in the laboratory of the Molecular and Macromolecular Studies of the Polish Academy of Science in Lodz, Poland. In addition, at 12 months of follow-up, blood samples were obtained at 7 a.m. after at least $14 \mathrm{~h}$ of fasting and then stored until further use.

In all of the patients, the serum concentrations of sodium, potassium, creatinine, CK-MB, troponin C, and lipids were assessed.

\section{Statistical analysis}

The analyses were performed using the Statistica 8.0 (StatSoft Polska, Krakow, Poland) software. The normality of the distribution was tested with the Shapiro-Wilk test. The analysis of variance was performed using Levene's test and the Brown-Forsythe test. Student's $t$-test for dependent and independent variables, the Mann-Whitney $U$ pair-wise comparison for independent variables, and the Wilcoxon pair-wise comparison for dependent variables were used as appropriate.
The correlation coefficients were calculated according to Spearman or Pearson. The diagnostic performance of the various biochemical parameters in predicting the improvement in LVEF or LV remodeling was assessed using receiver operating characteristic (ROC) curves. In addition, the cut-off values were determined for the evaluated variables using the Youden index. The odds ratios (ORs) and 95\% confidence intervals (Cls) were determined after the dichotomous recalculation of each parameter using the established cut-off values for the study group. Values of $p$ below 0.05 were considered to be statistically significant. All of the data presented are expressed as the means and standard deviations.

\section{Results}

The baseline clinical characteristics of the studied patients are presented in Table I. The study population consisted of 69 patients. The patients were divided into two groups according to the definition of MeS by the (NCEP-ATP-III) IDF: 36 patients (31 males, 5 females, mean age: $57 \pm 8$ ) with metabolic syndrome and 33 patients (18 males, 15 females, mean age: $60 \pm 12$ ) without metabolic syndrome. The female-to-male ratio was significantly higher in the group diagnosed with MeS. The body mass, BMI, WHR, and presence of diabetes were statistically significantly higher in the patients with MeS than in the patients without MeS at baseline. The two groups were uniform with respect to the baseline levels of total cholesterol, LDL, triglycerides, troponin, CK-MB mass and echo parameters. There were no significant changes in the drug therapy administered ( $\beta$-blockers, statins, angiotensin-converting-enzyme inhibitors, diuretics), except in the treatment of diabetes. The patients without metabolic syndrome showed an increase in the levels of ghrelin and leptin, whereas the resistin lev- 
A

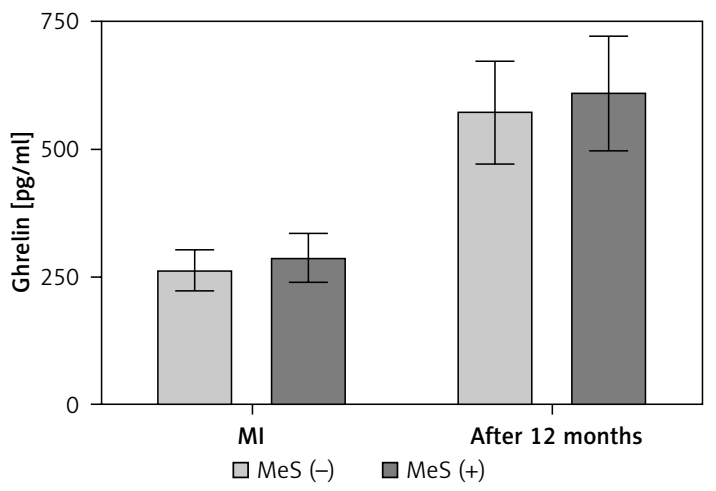

C

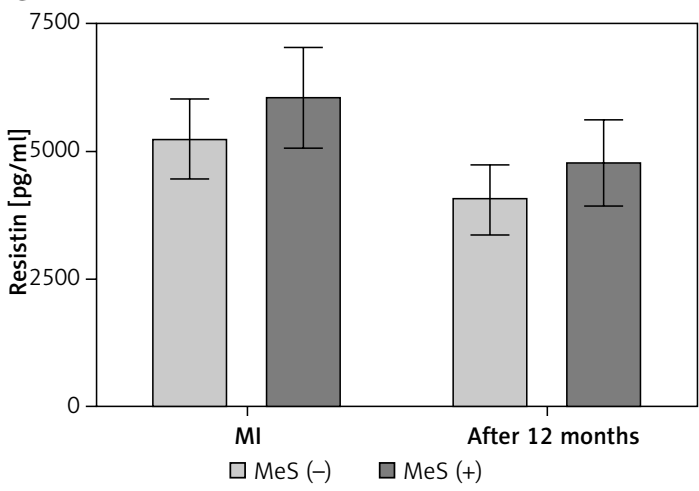

els decreased when comparing the acute phase samples with those obtained after 12 months of follow-up (Figure 1, Table III). However, only the ghrelin levels were significantly different after 12 months in the patients with MeS. In the acute phase, the levels of leptin were statistically significantly lower in the group without MeS than in the group with MeS (75 mg/dl vs. $205 \mathrm{mg} / \mathrm{dl}$, $p=0.0009$ ), whereas the ghrelin and resistin levels did not differ between the groups. The concentrations of leptin $(>52.18 \mathrm{pg} / \mathrm{ml}$ ) and resistin ( $>4419.27 \mathrm{ng} / \mathrm{ml}$ ) were independent predictive factors for improvement of the LVEF in the patients without MeS after a myocardial infarction (Figures 2, 3). In the patients with MeS, none of the adipokines reached a positive predictive value for the improvement of the LVEF. Additionally, the leptin, ghrelin and resistin levels were regarded as predictors of the occurrence of left ventricle
B

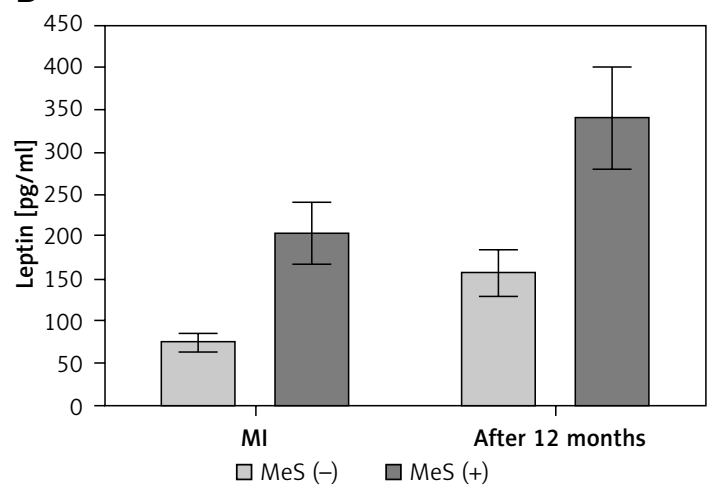

Figure 1. Concentrations of ghrelin (A), leptin (B) and resistin (C) at baseline and after 12 months in both study groups

MI - myocardial infarction, MeS(-) - patients without metabolic syndrome, MeS(+) - patients with metabolic syndrome.

remodeling. The levels of ghrelin $(\leq 160.46 \mathrm{pg} /$ $\mathrm{ml})$ and leptin $(\leq 20.51 \mathrm{pg} / \mathrm{ml})$ were independent predictors of left ventricular remodeling in the patients without MeS, whereas in the patients with MeS only the level of resistin $(\leq 5196.02 \mathrm{pg} / \mathrm{ml})$ reached such a predictive value (Figures 4-6). In both groups, the baseline echocardiographic parameters of the dimensions, systolic function and strain were fairly uniform (Table III) and represented moderate LV dysfunction. Selected parameters of the diameters, volumes, and LV systolic function measured after 12 months are presented in Table IV. Interestingly, there were no statistically significant differences in the global strain between the patients with MeS and without MeS measured shortly after the myocardial infarction; however, after 12 months of follow-up, the difference was statistically significant (16.8 vs. 15.9 , $p=0.02)($ Tables $\mathrm{V}, \mathrm{VI})$.

Table III. Levels of ghrelin, leptin and resistin in both groups at baseline and after 12 months of follow-up

\begin{tabular}{|c|c|c|c|c|c|c|}
\hline \multirow[t]{2}{*}{ Parameter } & \multicolumn{2}{|c|}{$\begin{array}{c}\text { Group I } \\
\text { Patients without metabolic } \\
\text { syndrome (33 patients) }\end{array}$} & \multirow[t]{2}{*}{$P$-value } & \multicolumn{2}{|c|}{$\begin{array}{c}\text { Group II } \\
\text { Patients with metabolic } \\
\text { syndrome (36 patients) }\end{array}$} & \multirow[t]{2}{*}{$P$-value } \\
\hline & $\begin{array}{c}\text { Baseline } \\
\text { (mean } \pm \text { SD) }\end{array}$ & $\begin{array}{l}12 \text { months } \\
\text { (mean } \pm S D)\end{array}$ & & $\begin{array}{c}\text { Baseline } \\
(\text { mean } \pm \text { SD) }\end{array}$ & $\begin{array}{l}12 \text { months } \\
\text { (mean } \pm D \text { ) }\end{array}$ & \\
\hline Ghrelin [pg/ml] & $263 \pm 166$ & $572 \pm 366$ & $<0.0001$ & $287 \pm 200$ & $609 \pm 355$ & $<0.0001$ \\
\hline Leptin [pg/ml] & $75 \pm 77$ & $158 \pm 129$ & 0.006 & $205 \pm 210$ & $341 \pm 308$ & 0.14 \\
\hline Resistin [ng/ml] & $5220 \pm 2945$ & $4039 \pm 2174$ & 0.033 & $6041 \pm 3430$ & $4760 \pm 2194$ & 0.112 \\
\hline
\end{tabular}




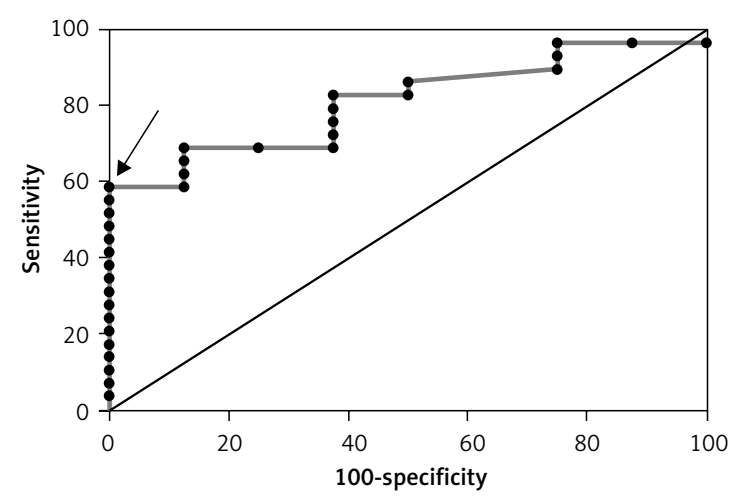

Figure 2. ROC curve for the improvement in LVEF (>5\%) based on leptin concentration in the group without MeS (AUC $=0.81$ and best cut-off value leptin > $52.18 \mathrm{pg} / \mathrm{ml})$

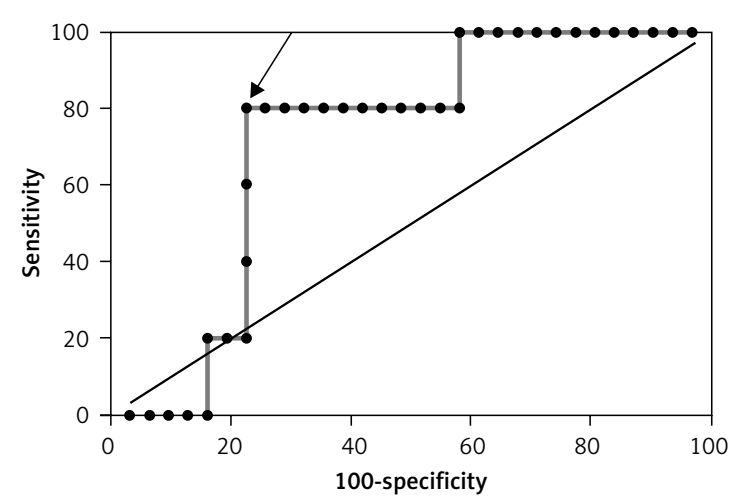

Figure 4. ROC curve for reverse cardiac remodeling (LVEDV > 8\%) based on ghrelin concentration in the group without MeS (AUC $=0.72$ and best cut-off value $<160.46 \mathrm{pg} / \mathrm{ml})$

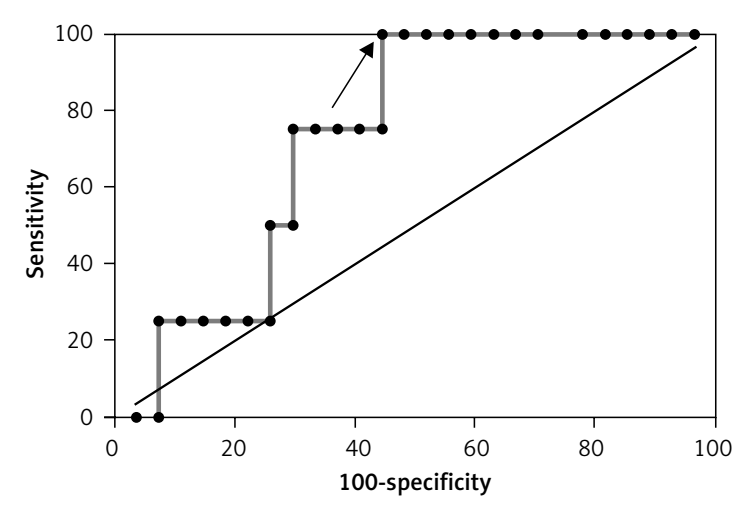

Figure 6. ROC curve for reverse cardiac remodeling (LVEDV > 8\%) based on resistin concentration in the group with MeS (AUC $=0.731$ and best cut off value $\leq 5196.02 \mathrm{pg} / \mathrm{ml})$

\section{Discussion}

We evaluated the relationships among the selected biomarkers, metabolic syndrome and the prognosis, improvement of cardiac function and cardiac remodeling in a group of patients with myocardial infarctions with ST elevation at 12 months of follow-up. The major finding of this

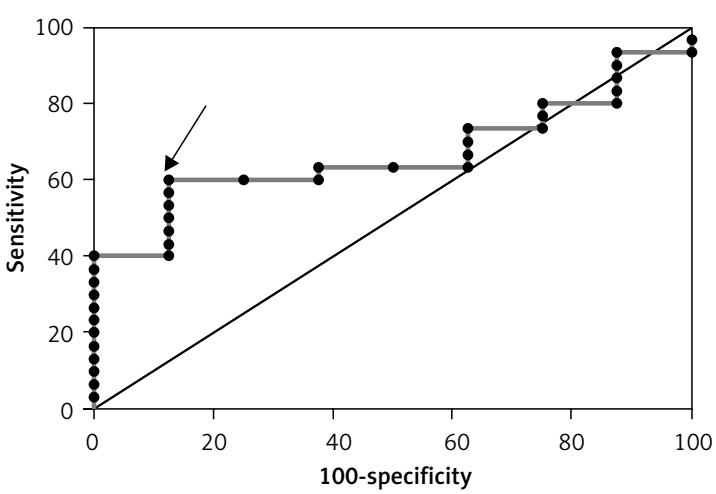

Figure 3. ROC curve for the improvement in LVEF (>5\%) based on resistin concentration in the group without MeS (AUC $=0.667$ and best cut off value $>4419.27 \mathrm{ng} / \mathrm{ml})$

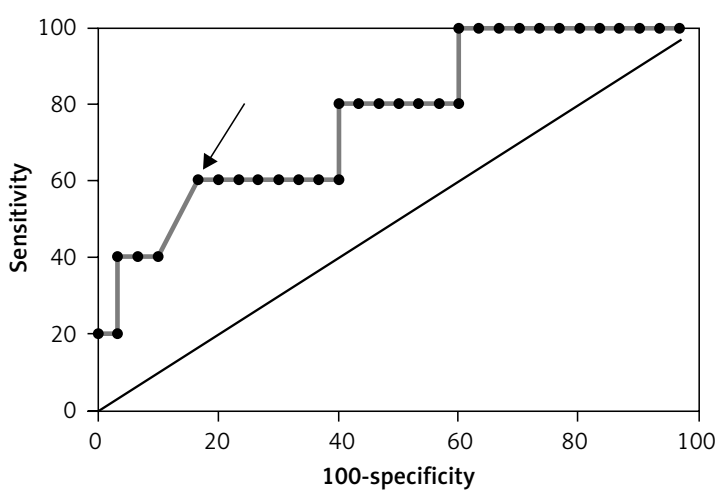

Figure 5. ROC curve for reverse cardiac remodeling (LVEDV > 8\%) based on leptin concentration in the group without MeS (AUC $=0.767$ and best cut-off value $<20.51 \mathrm{pg} / \mathrm{ml})$

study was that among the patients with a myocardial infarction, the selected adipokines may have a predictive value for the prognosis of improvement of the LVEF and the occurrence of LV remodeling according to the presence of MeS. We chose the (NCEP-ATP-III) IDF criteria because they are superior to IDF criteria in predicting acute STEMI severity in terms of clinical presentation, in-hospital complications and severity of CAD [14].

\section{Leptin}

In addition to reducing the appetite and controlling weight gain, leptin activates the sympathetic nervous system. Leptin's stimulation of adrenergic overdrive can lead to numerous adverse effects on the cardiovascular system. Both in vitro and in vivo studies have demonstrated adrenergic influences on the growth of cardiomyocytes [16]. Clinically, it is interesting to note that patients with a higher body mass index have a better outcome following an acute coronary syndrome or percutaneous coronary intervention [17]. In our study, we observed a higher concentration of leptin in the acute phase among patients with MeS. A previous 
Table IV. Respective predictive accuracies of ghrelin, leptin and resistin for the improvement of LVEF among patients 12 months after myocardial infarction, with and without metabolic syndrome

\begin{tabular}{|c|c|c|}
\hline $\begin{array}{l}\text { ROC curve analyses for } \\
\text { the improvement of LVEF }\end{array}$ & $\begin{array}{c}\text { Group I } \\
\text { Patients without metabolic syndrome } \\
(33 \text { patients) } \\
\text { AUC }(95 \% \mathrm{Cl}), p \text {-value }\end{array}$ & $\begin{array}{c}\text { Group II } \\
\text { Patients with metabolic syndrome } \\
(36 \text { patients) } \\
\text { AUC }(95 \% \mathrm{Cl}), p \text {-value }\end{array}$ \\
\hline Ghrelin & $0.69(0.526-0.834), 0.078$ & $0.53(0.353-0.704), 0.856$ \\
\hline Leptin & $0.81(0.648-0.920),<0.0001$ & $0.58(0.396-0.754), 0.795$ \\
\hline Resistin & $0.67(0.495-0.811), 0.049$ & $0.53(0.353-0.704), 0.765$ \\
\hline
\end{tabular}

ROC - receiver operating curves, LVEF - left ventricular ejection fraction.

Table V. Respective predictive accuracies of ghrelin, leptin and resistin for left ventricular remodeling in 12 months of follow-up in patients after myocardial infarction, with and without metabolic syndrome

\begin{tabular}{|c|c|c|}
\hline $\begin{array}{l}\text { ROC curve analyses } \\
\text { for left ventricular } \\
\text { remodeling (LVEDV > 8\%) }\end{array}$ & $\begin{array}{c}\text { Group I } \\
\text { Patients without metabolic syndrome } \\
(33 \text { patients }) \\
\text { AUC }(95 \% \mathrm{Cl}), p \text {-value }\end{array}$ & $\begin{array}{c}\text { Group II } \\
\text { Patients with metabolic syndrome } \\
(36 \text { patients }) \\
\text { AUC }(95 \% \mathrm{Cl}), p \text {-value }\end{array}$ \\
\hline Ghrelin & 0.72 (0.5542-0.853), 0.032 & $0.63(0.438-0.795), 0.476$ \\
\hline Leptin & $0.767(0.593-0.892), 0.030$ & $0.64(0.431-0.8), 0.667$ \\
\hline Resistin & $0.632(0.456-0.786), 0.239$ & $0.73(0.543-0.874), 0.024$ \\
\hline
\end{tabular}

LVEDV - left ventricular end diastolic volume.

Table VI. Echocardiographic parameters of the study group at baseline and after 12 months of follow-up

\begin{tabular}{|c|c|c|c|c|c|c|}
\hline \multirow[t]{2}{*}{ Variable } & \multicolumn{2}{|c|}{$\begin{array}{c}\text { Group I } \\
\text { Patients without MeS } \\
\text { (33 patients) } \\
\text { (mean } \pm \text { SD) }\end{array}$} & \multirow[t]{2}{*}{$P$-value } & \multicolumn{2}{|c|}{$\begin{array}{c}\text { Group II } \\
\text { Patients with MeS } \\
\text { (36 patients) } \\
\text { (mean } \pm \text { SD) }\end{array}$} & \multirow[t]{2}{*}{$P$-value } \\
\hline & Baseline & 12 months & & Baseline & 12 months & \\
\hline $\begin{array}{l}\text { Left ventricular end-diastolic } \\
\text { diameter }[\mathrm{mm}]\end{array}$ & $47 \pm 6$ & $49 \pm 6$ & 0.005 & $47 \pm 4$ & $48 \pm 6$ & $0.02^{*}$ \\
\hline $\begin{array}{l}\text { Left ventricular end-systolic } \\
\text { diameter }[\mathrm{mm}]\end{array}$ & $33 \pm 5$ & $33 \pm 4$ & 0.62 & $33 \pm 4$ & $33 \pm 4$ & 0.75 \\
\hline Left atrial diameter [mm] & $40 \pm 4$ & $42 \pm 4$ & 0.005 & $41 \pm 4$ & $40 \pm 4$ & 0.06 \\
\hline Right ventricular diameter [mm] & $26 \pm 3$ & $26 \pm 2$ & 0.063 & $26 \pm 3$ & $26 \pm 2$ & 0.04 \\
\hline $\begin{array}{l}\text { Left ventricular end-systolic } \\
\text { volume }[\mathrm{ml}]\end{array}$ & $68 \pm 16$ & $66 \pm 18$ & 0.14 & $68 \pm 12$ & $66 \pm 11$ & 0.01 \\
\hline $\begin{array}{l}\text { Left ventricular end-diastolic } \\
\text { volume }[\mathrm{ml}]\end{array}$ & $127 \pm 19$ & $128 \pm 22$ & 0.42 & $128 \pm 22$ & $129 \pm 20$ & 0.19 \\
\hline $\mathrm{EF}(\%)$ & $43 \pm 8$ & $50 \pm 7.7$ & $<0.001$ & $44 \pm 8$ & $52 \pm 7$ & $<0.0001$ \\
\hline 2-dimensional strain & $14.1 \pm 8$ & $16.8 \pm 8$ & $<0.001$ & $13.2 \pm 7$ & $15.9 \pm 8$ & $<0.001$ \\
\hline
\end{tabular}

EF-ejection fraction.

study of 58 patients similarly reported an elevated concentration of leptin in patients with MeS who experienced an MI [18]. Patients with metabolic syndrome have increased sympathetic activity, hypertension, and a higher incidence rate of left ventricular hypertrophy (LVH) [19]. The endomyocardial biopsies from the majority of obese patients with cardiomyopathy indicate myocyte hypertrophy as the underlying cause [20]. Hyperleptinemia is also observed in patients with LVH [21]. An animal model has confirmed that a 4- to 6-week leptin infusion reduced weight and reversed the $\mathrm{LVH}$, whereas caloric restriction reduced the weight but did not ef- fectively reduce the wall thickness and myocyte size [22]. Also insulin resistance is associated with $\mathrm{LVH}$, and this may explain why leptin has a predictive function for remodeling only among patients without MeS $[23,24]$. In the present investigation, we observed that elevated leptin levels correlated with an improved EF > 5\% at 12 months of follow-up, but only in the patients without MeS, which may be caused by severe impairment of the endothelial function in the group with MeS. Hyperleptinemia is associated with obesity-related hypertension and chronic congestive heart failure (HF) in humans and with vascular endothelial and myocardial dysfunc- 
tion in animal models [25]. Interestingly, several experimental studies have reported that leptin may have a vasorelaxant influence on the endothelium, which is impaired in pathological conditions such as obesity and metabolic syndrome [26]. A recent report showed that exogenous leptin given in an early reperfusion in an isolated mouse heart model reduced the infarct size [27]. A recent paper by Barouch et al. showed that leptin deficiency or resistance results in increased cardiomyocyte apoptosis [28]. It has been suggested that the interdependence of ET-1 and leptin signaling plays a role in the progression of myocardial dysfunction and hypertrophy and that leptin may cause chronic oxidative stress and inflammation in the myocardium, similar to other agents such as tumor necrosis factor (TNF)- $\alpha$, norepinephrine and Ang II, all of which induce hypertrophy via reactive oxygen species (ROS) upregulation [29]. Moreover, in a large Japanese study, lower leptin levels were associated with a high incidence of adverse events in patients after an AMI [30].

However, despite the power of leptin alone being limited, it may be useful in conjunction with other biomarkers: the association between leptin, adiponectin and traditional CV risk performed significantly better in predicting coronary heart disease when compared to a model that included only the conventional risk factors, especially in the intermediate risk group [31].

\section{Resistin}

In our study, the resistin levels were lower in the acute phase among the patients without MeS than in the patients with MeS $(p=0.033)$ and decreased in both groups after 12 months of follow-up, although the decrease was statistically significant only among the patients without MeS $(p=0.049)$. Similar results were obtained by Lubos et al., who observed elevated resistin levels in patients presenting with unstable angina, non-ST-segment elevation myocardial infarction (NSTEMI) and STEMI and concluded that resistin levels might play a role as a diagnostic marker [32]. In animal models it was proved that resistin leads to insulin resistance and dyslipidemia, and the concentration in plasma increases with obesity $[33,34]$. A large cohort study on approximately 2000 patients showed a strong, independent association between higher resistin levels and the incidence of cardiovascular diseases (myocardial infarction, angina, resuscitated cardiac arrest, stroke and heart failure) [35].

Based on a cohort study, Weikert et al. suggested that elevated resistin levels may be a predictor of myocardial infarction development [36]. In a paper published by Chu et al. the resistin plasma levels in the patients with ACS were significantly elevated within the first week after the onset of symptoms and correlated positively with the levels of plasma myocardium injury markers and negatively with LVEF [37]. In patients undergoing cardiothoracic surgery, the levels of resistin were correlated with oxidative stress and myocardial injury [38]. In a recently published paper, resistin was considered to be an independent risk factor of recurrent $\mathrm{AMI} /$ unstable angina among patients with coronary artery disease [39]. In study by Takata et al. it was confirmed that resistin correlates with hypertension but only in patients with type 2 diabetes mellitus [40].

Our study showed that a decreased level of resistin $(\leq 5196.02 \mathrm{pg} / \mathrm{ml})$ was a predictor of left ventricle remodeling, but only among patients with metabolic syndrome. Previous studies confirmed that the level of resistin correlates positively with cardiac fibrosis, especially among patients with chronic ischemia [41]. However, an interesting paper by Gao et al. confirmed that resistin can have a cardioprotective effect and can dramatically reduce apoptosis and infarct size, thus protecting the heart against an I/R injury [42]. In our study the protective effect of resistin in the MeS group may be due to higher levels of resistin, and it may lead to changes in the density of the resistin receptors as well as effective revascularization. However, this hypothesis must be evaluated by the identification of the density of the receptor CAP-1 for resistin among patients with MeS and those without it [43].

\section{Ghrelin}

The concentration of ghrelin is decreased among obese patients; however, it is closely correlated with their eating habits [44]. Moreover, after an MI, the level of ghrelin decreases by approximately $30 \%$ [45]. In our study, we observed no differences between the two groups of patients in the acute phase, followed by an increase in the ghrelin levels at 12 months in both of the groups. Recent studies have shown that ghrelin promotes human embryonic stem cell survival and differentiation in an infarcted cardiac microenvironment in the rat [46]. In the present investigation, the concentration of ghrelin $(\leq 160.46 \mathrm{pg}$ ) $\mathrm{ml}$ ) was an independent predictor of left ventricular remodeling in the patients without MeS. This corresponds with recently published data from an animal model showing that systemic administration of ghrelin partially reversed the adverse LV remodeling in mice after myocardial infarction [47]. Also Matsumoto et al. confirmed that in patients with $\mathrm{AMI}$, the ratio of the day 14 to the admission serum concentration of ghrelin was inversely correlated with the left ventricular ejection fraction $(r=-0.53, p<0.05)$, and the levels were significantly decreased in association with the myocardial infarct size and cardiac function [48]. 
Huang et al. confirmed that ghrelin administration significantly decreased the post-MI LV remodeling, inhibited the inflammatory response by decreasing the levels of interleukin-1 $\beta$, tumor necrosis factor- $\alpha$ (TNF- $\alpha$ ) and the expression of matrix metalloproteinases MMP-2 and MMP-9 [49]. A study in an animal model demonstrated that the subcutaneous administration of ghrelin improved LV dysfunction and attenuated early cardiac remodeling after $\mathrm{Ml}$; this effect might have been mediated by the suppression of cardiac sympathetic nerve activity as well as by the preventive effects of ghrelin, which may be mediated by the anti-inflammatory actions of the PPAR- $\gamma$-dependent pathway [50, 51]. In an animal model, Du et al. found that ghrelin reduced the LV end-diastolic dimensions, increased the LV ejection fraction and prevented cardiac remodeling and fibrosis through suppression of excessive cardiac sympathetic nerve activity [52].

Interestingly, in our study we observed an inverse correlation between the changes in the ghrelin levels and the EF in 12 months of follow-up, but only in the patients with MeS.

In conclusion, our results show that the adipokines play an important role in the prediction of LVEF improvement and in the occurrence of cardiac remodeling in patients with myocardial infarctions. The concentrations of leptin and resistin were independent predictive factors for improvement of the LVEF in the patients without MeS after myocardial infarctions, which was not the case in the patients with MeS. In the 12-month follow-up, the levels of leptin and ghrelin were independent predictors of left ventricular remodeling in the patients without MeS, and in the patients with MeS only the level of resistin was an independent predictor of left ventricular remodeling.

The selected adipokines plays an important role in the improvement of LV function after myocardial infarction dependent on MeS, and they may be a potential therapeutic target in the future.

\section{Conflict of interest}

The authors declare no conflict of interest.

\section{References}

1. Simmons RK, Alberti KG, Gale EA, et al. The metabolic syndrome: useful concept or clinical tool? Report of a WHO Expert Consultation. Diabetologia 2010; 53: 600-5.

2. Cook S, Auinger P, Li C, Ford ES. Metabolic syndrome rates in United States adolescents, from the National Health and Nutrition Examination Survey, 1999-2002. J Pediatr 2008; 152: 165-70.

3. Erwin RB. Prevalence of metabolic syndrome among adults 20 years of age and over by sex, age, race and ethnicity, and body mass index: United States 2003-
2006. National Health Statistics Reports; No.13. Hyattsville, MD: National Center for Health Statistics. 2009. http://www.cdc.gov/nchs/data/nhsr/nhsr013.pdf. Accessed January 1, 2011.

4. Gami AS, Witt BJ, Howard DE, et al. Metabolic syndrome and the risk of incident cardiovascular events and death: a systematic review and meta-analysis of longitudinal studies. J Am Coll Cardiol 2007; 49: 403-14.

5. Dallmeier D, Larson M, Vasan R, et al. Metabolic syndrome and inflammatory biomarkers: a communitybased cross-sectional Study at the Framingham Heart Study. Diabetol Metab Syndr 2012; 4: 28.

6. Roger VL, Go AS, Lloyd-Jones DM, et al. American Heart Association Statistics Committee and Stroke Statistics Subcommittee Heart disease and stroke statistics--2011 update: a report from the American Heart Association. Circulation 2011; 123: e18-20.

7. Yeh RW, Sidney S, Chandra M, Sorel M, Selby JV, Go AS. Population trends in the incidence and outcomes of acute myocardial infarction. NEJM 2010; 362: 2155-65.

8. Fain JN, Cheema PS, Bahouth SW, Lloyd Hiler M. Resistin release by human adipose tissue explants in primary culture. Biochem Biophys Res Commun 2003; 300: 674-8.

9. Banerjee RR, Lazar MA. Resistin: molecular history and prognosis. J Mol Med (Berl) 2003; 81: 218-26.

10. Sato N, Kobayashi K, Inoguchi T, et al. Adenovirus-mediated high expression of resistin causes dyslipidemia in mice. Endocrinology 2005; 146: 273-9.

11. Kreçki R, Krzemińska-Pakuła M, Peruga JZ, et al. Elevated resistin opposed to adiponectin or angiogenin plasma levels as a strong, independent predictive factor for the occurrence of major adverse cardiac and cerebrovascular events in patients with stable multivessel coronary artery disease over 1-year follow-up. Med Sci Monit 2011; 17: CR26-32.

12. Li Z, Zhu XY, Li M, Bai YL, Hu J. Protective effect of ghrelin on left ventricular remodeling in spontaneously hypertensive rats is associated with the peroxisome proliferator-activated receptor gamma-dependent pathway. Chin Med J (Engl) 2008; 121: 2299-304.

13. http://www.idf.org/webdata/docs/IDF_Meta_def_final. pdf

14. Jelavic MM, Babic Z, Hrvoje P. The importance of two metabolic syndrome diagnostic criteria and body fat distribution in predicting clinical severity and prognosis of acute myocardial infarction. Arch Med Sci DOI: 10.5114/aoms.2016.59703.

15. Nicolosi GL, Golcea S, Ceconi C, et al. Effects of perindopril on cardiac remodelling and prognostic value of pre-discharge quantitative echocardiographic parameters in elderly patients after acute myocardial infarction: the PREAMI echo sub-study. Eur Heart J 2009; 30: 1656-65.

16. Patel MB, Stewart JM, Loud AV, et al. Altered function and structure of the heart in dogs with chronic elevation in plasma norepinephrine. Circulation 1991; 84: 2091-100.

17. Nikolsky E, Stone GW, Grines CL, et al. Impact of body mass index on outcomes after primary angioplasty in acute myocardial infarction. Am Heart J 2006; 151: 168-75.

18. Krasnodębski P, Bąk MI, Opolski G, Karnafel W. Leptin in acute myocardial infarction and period of convalescence in patients with type 2 diabetes mellitus. Kardiol Pol 2010; 68: 648-53.

19. Navarro J, Redon J, Cea-Calvo L, et al. Metabolic syndrome, organ damage and cardiovascular disease in treated hypertensive patients. the ERIC-HTA study. Blood Press 2007; 16: 20-7. 
20. Kasper EK, Hruban RH, Baughman KL. Cardiomyopathy of obesity: a clinicopathologic evaluation of 43 obese patients with heart failure. Am J Cardiol 1992; 70: 921-4

21. Sader S, Nian M, Liu P. Leptin: a novel link between obesity, diabetes, cardiovascular risk, and ventricular hypertrophy. Circulation 2003; 108: 644-6.

22. Barouch LA, Cappola TP, Harrison RW, et al. Combined loss of neuronal and endothelial nitric oxide synthase causes premature mortality and age-related hypertrophic cardiac remodeling in mice. J Mol Cell Cardiol 2003; 35: 637-44.

23. Hintz KK, Aberle NS, Ren J. Insulin resistance induces hyperleptinemia, cardiac contractile dysfunction but not cardiac leptin resistance in ventricular myocytes. Int J Obes Relat Metab Disord 2003; 10: 1196-203.

24. Paolisso G, Tagliamonte MR, Galderisi M, et al. Plasma leptin level is associated with myocardial wall thickness in hypertensive insulin-resistant men. Hypertension 1999; 34: 1047-52.

25. Morawietz H, Bornstein SR. Leptin, endothelin, NADPH oxidase, and heart failure. Hypertension 2006; 47: e20.

26. Beltowski J. Leptin and the regulation of endothelial function in physiological and pathological conditions. Clin Exp Pharmacol Physiol 2012; 39: 168-78.

27. Smith CC, Mocanu MM, Davidson SM, Wynne AM, Simpkin JC, Yellon DM. Leptin, the obesity-associated hormone, exhibits direct cardioprotective effects. $\mathrm{Br}$ J Pharmacol 2006; 149: 5-13.

28. Barouch LA, Gao D, Chen L, et al. Cardiac myocyte apoptosis is associated with increased DNA damage and decreased survival in murine models of obesity. Circ Res 2006; 98: 119-24.

29. Yamashita T, Murakami T, lida M, Kuwajima M, Shima K. Leptin receptor of zucker fatty rat performs reduced signal transduction. Diabetes 1997; 46: 1077-80.

30. Morita Y, Maeda K, Kondo T, et al. Impact of adiponectin and leptin on long-term adverse events in Japanese patients with acute myocardial infarction. Results from the Nagoya Acute Myocardial Infarction Study (NAMIS). Circ J 2013; 77: 2778-85.

31. Hogas S, Bilha SC, Branisteanu D, et al. Potential novel biomarkers of cardiovascular dysfunction and disease: cardiotrophin-1, adipokines and galectin-3. Arch Med Sci DOI: 10.5114/aoms.2016.58664

32. Lubos E, Messow CM, Schnabel R, et al. Resistin, acute coronary syndrome and prognosis results from the AtheroGene study. Atherosclerosis 2007; 193: 121-8.

33. Sato N, Kobayashi K, Inoguchi T, et al. Adenovirus mediated high expression of resistin causes dyslipidemia in mice. Endocrinology 2005; 146: 273-9.

34. Satoh H, Nguyen MT, Miles PD, et al. Adenovirus mediated chronic "hyper-resistinemia" leads to in vivo insulin resistance in normal rats. J Clin Invest 2004; 114: 224-31.

35. Muse ED, Feldman DI, Blaha MJ, et al. The association of resistin with cardiovascular disease in the Multi-Ethnic Study of Atherosclerosis. Atherosclerosis 2014; 239: 101-8

36. Weikert C, Westphal S, Berger K, et al. Plasma resistin levels and risk of myocardial infarction and ischemic stroke. J Clin Endocrinol Metab 2008; 93: 2647-53.

37. Chu S, Ding W, Li K, Pang Y, Tang C. Plasma resistin associated with myocardium injury in patients with acute coronary syndrome. Circ J 2008; 72: 1249-53.

38. Laurikka A, Vuolteenaho K, Toikkanen V, et al. Adipocytokine resistin correlates with oxidative stress and myo- cardial injury in patients undergoing cardiac surgery. Eur J Cardiothorac Surg 2014; 46: 729-36.

39. Grzywocz P, Mizia-Stec K, Wybraniec M, Chudek J. Adipokines and endothelial dysfunction in acute myocardial infarction and the risk of recurrent cardiovascular events. J Cardiovasc Med (Hagerstown) 2015; 16: 37-44.

40. Takata Y, Osawa $\mathrm{H}$, Kurata $\mathrm{M}$, et al. Hyperresistinemia is associated with coexistence of hypertension and type 2 diabetes. Hypertension 2008; 51: 534-9.

41. Lebeche D. Diabetic cardiomyopathy: is resistin a culprit? Cardiovasc Diagn Ther 2015; 5: 387-93.

42. Gao J, Chang Chua C, Chen Z, et al. Resistin, an adipocytokine, offers protection against acute myocardial infarction. J Mol Cell Cardiol 2007; 43: 601-9.

43. Lee S, Lee HC, Kwon YW, et al. Adenylyl cyclase-associated protein 1 is a receptor for human resistin and mediates inflammatory actions of human monocytes. Cell Metab 2014; 19: 484-97.

44. le Roux C, Patterson M, Vincent R, Hunt C, Ghatei M, Bloom S. Postprandial plasma ghrelin is suppressed proportional to meal calorie content in normal weight but not obese subjects. J Clin Endocrinol Metab 2004; 90: 1068-71.

45. Pemberton C, Wimalasena P, Yandle T, Soule S, Richards M. C-terminal pro-ghrelin peptides are present in the human circulation. Biochem Biophys Res Commun 2003; 310: 567-73.

46. Gao M, Yang J, Liu G, et al. Ghrelin promotes the differentiation of human embryonic stem cells in infarcted cardiac microenvironment. Peptides 2012; 34: 373-9.

47. Yuan MJ, Kong B, Wang T, Wang X, Huang $H$, Maghsoudi T. Ghrelin protects infarcted myocardium by induction of autophagy and AMP-activated protein kinase pathway. Biochem Biophys Res Commun 2016; 476: 365-70.

48. Matsumoto M, Yasuda S, Miyazaki S, et al. Decreased serum ghrelin levels in patients with acute myocardial infarction. Tohoku J Exp Med 2013; 231: 235-42.

49. Huang CX, Yuan MJ, Huang $H$, et al. Ghrelin inhibits post-infarct myocardial remodeling and improves cardiac function through anti-inflammation effect. Peptides 2009; 30: 2286-91.

50. Soeki T, Kishimoto I, Schwenke DO, et al. Ghrelin suppresses cardiac sympathetic activity and prevents early left ventricular remodeling in rats with myocardial infarction. Am J Physiol Heart Circ Physiol 2008; 294: H426-32.

51. Li Z, Zhu XY, Li M, Bai YL, Hu J. Protective effect of ghrelin on left ventricular remodeling in spontaneously hypertensive rats is associated with the peroxisome proliferator-activated receptor gamma-dependent pathway. Chin Med J (Engl) 2008; 121: 2299-304.

52. Du CK, Zhan DY, Morimoto S, et al. Survival benefit of ghrelin in the heart failure due to dilated cardiomyopathy. Pharmacol Res Perspect 2014; 2: e0006. 